\title{
Comparison of Different Control Algorithms for a Gantry Crane System
}

\author{
Stefan Bruins \\ HAN University, Arnhem and Nijmegen, The Netherlands \\ E-mail: js_bruins@hotmail.com \\ Received June 22, 2010; revised September 4, 2010; accepted September 15, 2010
}

\begin{abstract}
For a gantry crane system, this paper presents a comparison between four control algorithms. These algorithms are being compared on simplicity, stability and robustness. Goal for the controller is to move the load on a gantry crane to a new position with minimal overshoot of the load and maximal speed of the load. Another goal is to provide an insight in the behaviour of the possible controllers. In this article a parallel P-controller, cascade P-controller, fuzzy controller and an internal model controller are used. To be able to validate and design the controllers a model is derived from the gantry crane. The controllers and the model are being implemented in Matlab Simulink. Finally the controllers are validated and tuned in Labview on a laboratory gantry scrane scale model. Main conclusion is that all presented controllers can be used as a controller for the gantry crane system but the fuzzy controller is showing the best performance.
\end{abstract}

Keywords: Gantry Crane, Modelling, Control, Fuzzy, Internal Model Control, Control Algorithms, Scale Model, Labview, Matlab, Simulink

\section{Introduction}

A gantry crane is a popular process for educational purposes in the field of control engineering. Most important is that the system is suitable for the demonstration of a wide range of control algorithms. With the ongoing improvement of tooling the testing and implementation trajectory of control algorithms has become more efficient and therefore faster.

To be able to get a good insight in the exact behaviour of a controller and, of course, a process a demonstration system is necessary. In this paper a scale model is used for the demonstration of each of the controllers.

The focus on this paper is the demonstration of the controllers instead of finding the best possible controller for this. Therefore the controllers are being used are very straightforward and well documented in the control theory instead of trying to find the best customized controller for this specific task.

This paper is organized as follows. Section 2 presents the gantry crane system and a mathematical model of this system is derived. Section 3 introduces the four control algorithms. In section 4 the simulation of the controllers within Matlab Simulink is discussed. Section 5 the validation of the controllers in Labview. Finally in section 6 conclusions are being made.

\section{Gantry Crane System}

Figure 1 shows a typical gantry crane system. Such a crane is used in harbors for the loading and unloading of containers to and from ships. The crane (M) is moved by a transport belt which is connected to a motor controlled by a frequency converter. During the movement the load (m) will oscillate relative to the crane. Normally the operator of the crane will control the motor in such a way

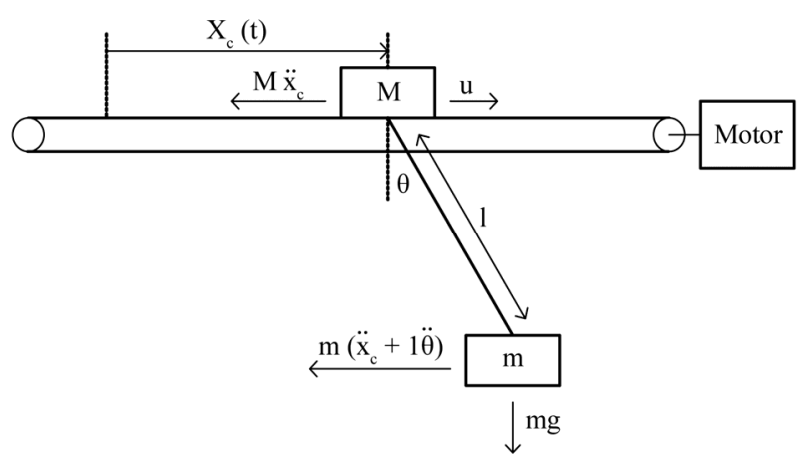

Figure 1. Schematic overview of gantry crane system with forces on load (m). 
that this movement will be limited. This oscillating can cause that the load or the truck is damaged during the loading process.

On the laboratory scale model the load and the length of the cable between the load and the crane is fixed. Also the joints and the cable between the load and the crane are fixed.

The goal of the controller is to move the load (m) to a new position (x) with a minimal overshoot as fast as possible.

The components used for the gantry crane scale model are listed in Table 1.

To be able to model the gantry crane system a decomposition in four parts can be done. A model for the motor, the transport belt, the mass (M) and the load (m).

\subsection{Modelling of the Motor}

For the motor a state space model is derived. First step was the choice of states, inputs and outputs for this model

$$
\begin{aligned}
& x_{1}=i(t), x_{2}=\frac{d}{d t} \theta(t)=\omega(t) \\
& u_{1}=v_{a}(t) \\
& y_{1}=\omega(t)
\end{aligned}
$$

Where $i(t)$ is the motor current, $\theta(t)$ is the angular position, $\omega(t)$ is the angular velocity and $v_{a}(t)$ is the motor voltage. The equations of the motor

$$
\begin{aligned}
& v_{a}(t)=L \frac{d}{d t} i(t)+R i(t)+K_{b} \omega(t) \\
& J \frac{d}{d t} \omega(t)+K_{f} \omega(t)=K_{m} i(t)
\end{aligned}
$$

Where $R$ is the resistance, $L$ is the inductance, $K_{b}$ is the emf constant, $\mathrm{K}_{\mathrm{m}}$ is the armature constant, $\mathrm{K}_{\mathrm{f}}$ is the linear approximation of viscous friction and $\mathrm{J}$ is the inertial load. These equations are being rearranged to be able to use these equations in a state space model

$$
\begin{aligned}
& \frac{d}{d t} i(t)=-\frac{R}{L}(t)-\frac{K_{b}}{L} \omega(t)+\frac{1}{L} v_{a}(t) \\
& \frac{d}{d t} \omega(t)=\frac{K_{m}}{L} i(t)-\frac{K_{f}}{L} \omega(t)
\end{aligned}
$$

With these information a state space model can be created

$$
\begin{aligned}
& \frac{d}{d t}\left[\begin{array}{l}
x_{1} \\
x_{2}
\end{array}\right]=\left[\begin{array}{cc}
-\frac{R}{L} & -\frac{K_{b}}{L} \\
\frac{K_{m}}{J} & 0
\end{array}\right]\left[\begin{array}{l}
x_{1} \\
x_{2}
\end{array}\right]+\left[\begin{array}{l}
\frac{1}{L} \\
0
\end{array}\right]\left[v_{a}(t)\right] \\
& {\left[y_{1}\right]=\left[\begin{array}{ll}
0 & 1
\end{array}\right]\left[\begin{array}{l}
x_{1} \\
x_{2}
\end{array}\right]+[0]\left[v_{a}(t)\right]}
\end{aligned}
$$

Then the generic formula for the conversion from a state space model to a transfer function is being applied

$$
H=C(s i-A)^{-1} B
$$

This results in the following transfer function of the motor.

$$
\frac{\omega}{v_{a}}=\frac{K_{m}}{s^{2} J L+s J R+K_{b} K_{m}}
$$

\subsection{Modelling of the Belt}

The belt has some damping. The damping of the belt will be neglected because the damping of the motor is dominant to the damping caused by the belt.

Table 1. Component list.

\begin{tabular}{lll}
\hline \multicolumn{1}{c}{ Part } & \multicolumn{1}{c}{ Manufacturer } & \multicolumn{1}{c}{ Type } \\
\hline Toothed belt axis & FESTO & DGE-ZR-KF 40mm size 1100 mm stroke length \\
Servo motor & FESTO & MTR-AC 100-3S \\
Servo motor controller & FESTO & SEC-AC-305 \\
Angle sensor & Contelec & RSC 3762 236 111 402 \\
Speed sensor & FESTO & On servo motor controller \\
Data acquisition & National instruments & NI cDAQ-9172 \\
Analog output module & National instruments & NI 9263 \\
Analog input module & National instruments & NI 9215 \\
Control software & National instruments & Labview 8.5 \\
\hline
\end{tabular}




\subsection{Modelling of the Mass}

For the mass the formula for the translation of rotational power to translation is used

$$
T_{\text {pulley }} \omega_{\text {pulley }}=F v_{\text {mass }}
$$

Where $\omega_{\text {pulley }}$ is the angular velocity of the pulley, $T_{\text {pul- }}$ ley is the torque of the pulley, $\mathrm{F}$ is the power and $\mathrm{V}_{\text {mass }}$ is the velocity of the mass. The velocity of the mass is equal to the velocity of the pulley

$$
v_{\text {mass }}=v_{\text {pulley }}
$$

Also

$$
v_{\text {pulley }}=\omega_{\text {pulley }} R_{\text {pulley }}
$$

Where $R_{\text {pulley }}$ is the radius of the pulley and $V_{\text {pulley }}$ is the velocity of the pulley. Now formula (7) can be rewritten as

$$
F=\frac{T_{\text {pulley }}}{R_{\text {pulley }}}
$$

The pulley has a certain efficiency regarding the transferring of power resulting in the following relationship

$$
T_{\text {pulley }}=\text { Eff }_{\text {pulley }} T_{\text {motor }}
$$

Where $T_{\text {motor }}$ is the torque of the motor and Eff $_{\text {pulley }}$ is the efficiency of the pulley. The torque of the motor can be rewritten as

$$
T_{\text {motor }}=\frac{J d \omega}{d t}
$$

Where $\mathrm{J}$ is the total momentum and $\omega$ is the angular velocity. This results in the following

$$
F=\frac{E f f_{\text {pulley }} \frac{J d \omega}{d t}}{R_{\text {pulley }}}
$$

Then this function is transferred to the s-domain

$$
\frac{F}{\omega}=\frac{E f f_{\text {pulley }} J S}{R_{\text {pulley }}}
$$

\subsection{Modelling of the Load}

Figure 1 is being used as a base for the calculations regarding the position of the load. The force in $\mathrm{x}$ direction

$$
M \frac{d^{2} x}{d t^{2}}+m \frac{d^{2} x}{d t^{2}}+m l \frac{d^{2} \theta}{d t^{2}}=u
$$

Substitute to $\mathrm{V}$

$$
M \frac{d v}{d t}+m \frac{d v}{d t}+m l \frac{d^{2} \theta}{d t^{2}}=u
$$

Then the torque is being balanced

$$
m\left(\frac{d^{2} x}{d t^{2}}+l \frac{d^{2} \theta}{d t^{2}}\right) l \cos (\theta)+m g l \sin (\theta)=0
$$

For the simulation and the modelling the approachment $\cos (\theta)=1 ; \sin (\theta)=\theta$ is used and substitution to $\mathrm{v}$ is done

$$
m\left(\frac{d^{2} x}{d t^{2}}+l \frac{d^{2} \theta}{d t^{2}}\right)+m g \theta=0
$$

With a mathematical tool such as Maple formula (16) and formula (18) can be used to create the transfer function for the speed of the load

$$
\frac{v}{u}=\frac{L s^{2}+G}{\left(I M s^{2}+g m+g M\right) s}
$$

This is also done for the angle of the load $(\theta / \mathrm{u})$

$$
\frac{\theta}{u}=\frac{-1}{l M s^{2}+g(m+M)}
$$

\section{Control Algorithms}

A lot of possible control algorithms could be used on a gantry crane system, such as parallel P-controller, cascade P-controller [1], fuzzy controller [5], internal model controller [6], LQR controller [2], MPC controller [3], MRAC controller [4]

Four control algorithms were implemented on the described gantry model. A parallel P-controller, cascade P-controller, fuzzy controller and an internal model controller were implemented. Reason for this choice is that these controllers could easily being implemented on a Labview system. In this paragraph a short description is given for each algorithm.

The LQR and MPC controller are based on cost functions and the only cost functions in our case are the setpoint deviations, the actuator movement is in this case no priority. The MRAC controller could be and interesting controller to investigate at a later stage.

The angle of the load and the speed of the motor are the inputs for the controller while the voltage to the motor is the output of the controller. Goals of the controller are move the load to a new position as fast as possible and limit the oscillation of the angle of the load.

Intuitive the behaviour of the moving of the load to the new position can be seen as an integrating process and the angle of the load as a stable process (the rod will reach zero position, even without control actions). These are important aspects when trying to understand the paradigm of each of the controllers.

\subsection{Parallel P-Controller}

With this controller for each control goal a separate con- 
troller is applied where the controllers are used in parallel. Figure 2 is the block diagram of this controller.

The control loop will consist of two controllers. The first controller is a slow P-controller to control the position of the motor. A P-controller is sufficient because the motor can be seen as an integrator from voltage to position and therefore this part will behave as an integrator and no static error will occur.

The second controller is a fast P-controller to control the angle of the load. Because the movement of the angle of the load is stable and the zero position is always reached a fast controller with no phase shift will suffice. Therefore we will use a P-controller.

\subsection{Cascade P-Controller}

With this controller an inner and an outer control loop are introduced. The outer loop controls to movement to the new position and the inner loop controls the angle of the load. Figure 3 is the block diagram of this controller.

The main philosophy behind this controller is that the angle of the load should not be controlled to a zero position but that the angle of the load should be dependant of the deviation in the position. When a constant acceleration is being applied on the gantry crane the angle of the load will settle to a value unequal to zero (formula 16).

The outer control loop will create a load angle setpoint causing a certain acceleration of the motor. As soon as the position setpoint has been reached to load angle setpoint will come to a negative setpoint causing the a deceleration and finally the stopping of the motor.

\subsection{Fuzzy Controller}

The actions performed by a fuzzy controller are dependant of a rule base. Based on the angle of the rod, the deviation in the position and the rule base the controller decides which voltage is being sent to the motor. Figure 4 is the block diagram of this controller.

First step when creating a fuzzy controller is the definition of the membership functions. Figure 5. shows the membership function for the position deviation.

Next step is the creation of the membership function for the voltage to the motor. Figure 6 shows the membership function for the voltage of the motor.

Last step for the creation of the fuzzy controller is the.

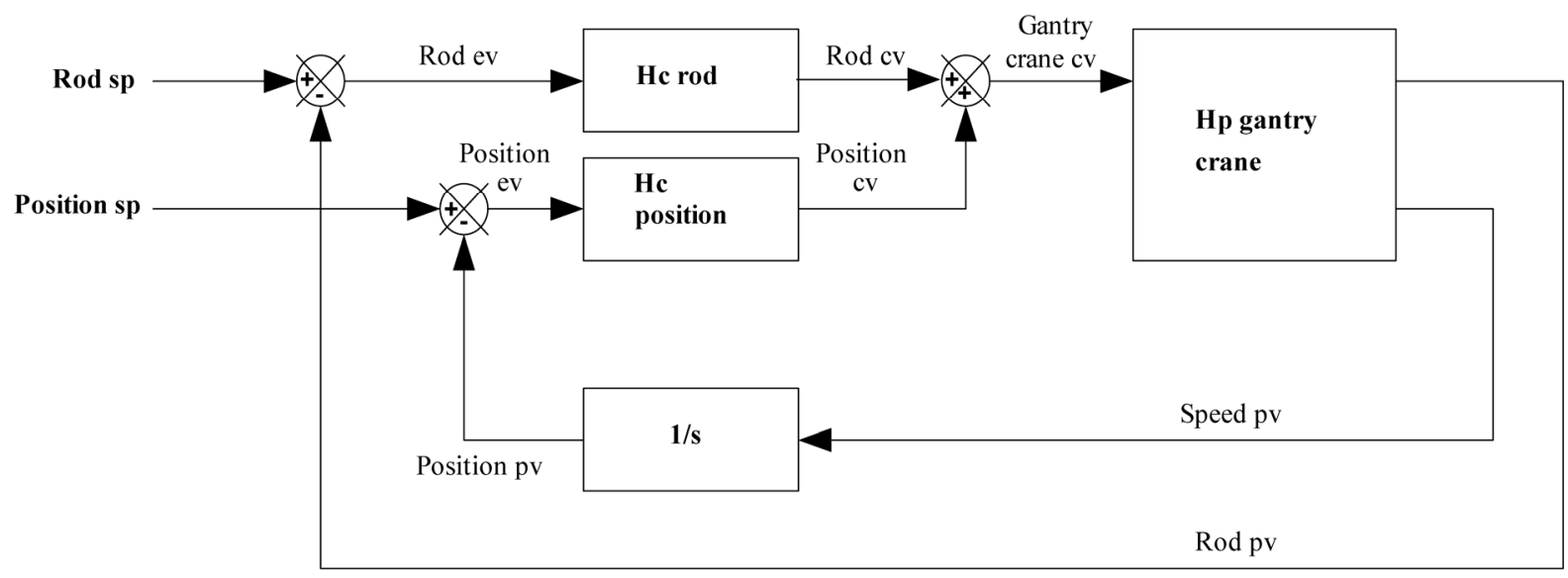

Figure 2. Block diagram of the parallel P-controller.

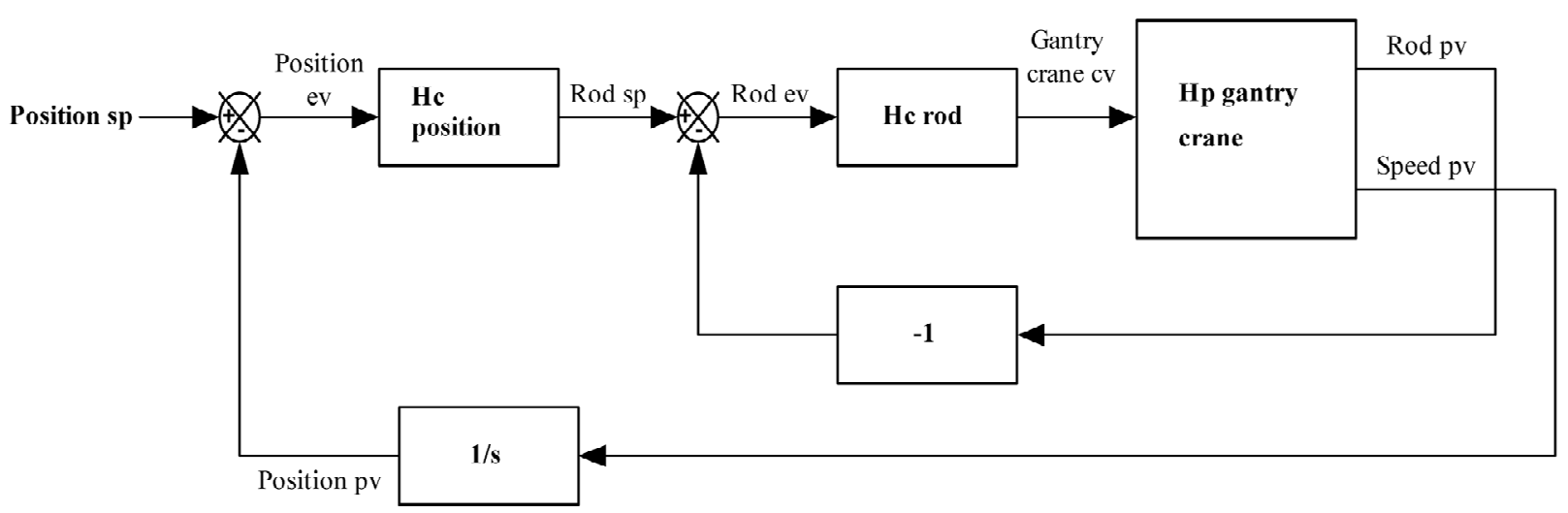

Figure 3. Block diagram of the cascade P-controller. 


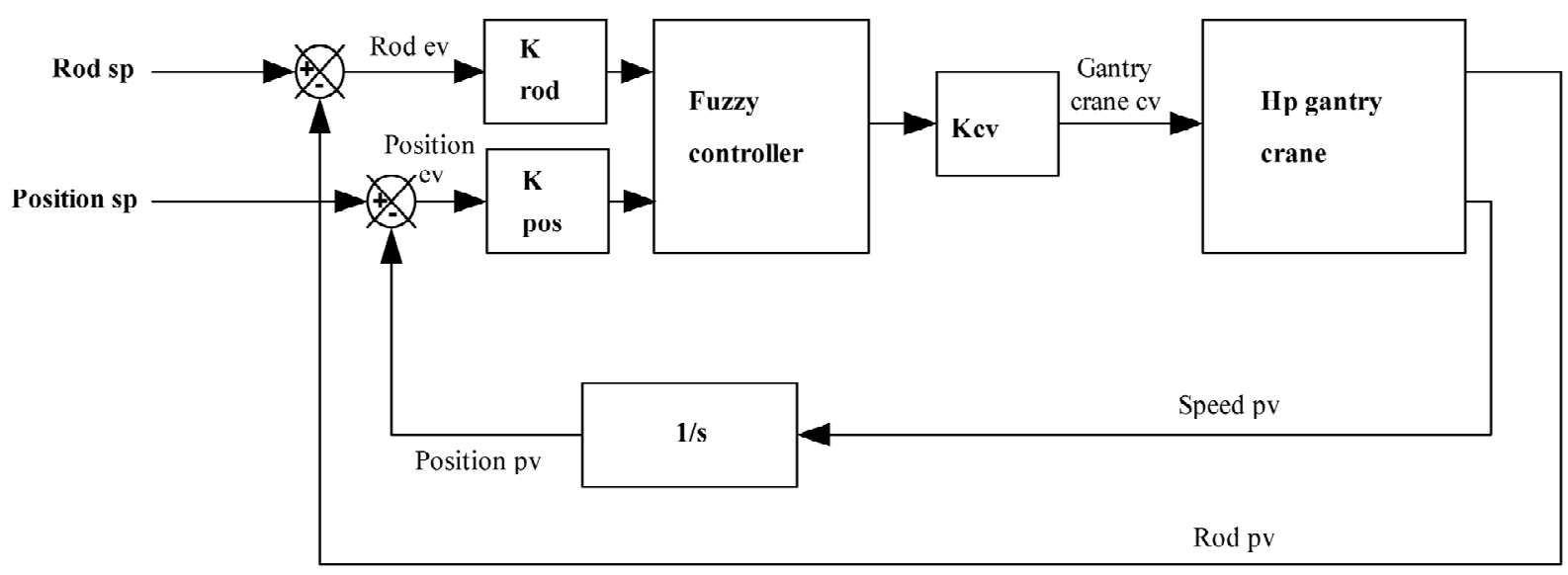

Figure 4. Block diagram of the fuzzy controller.

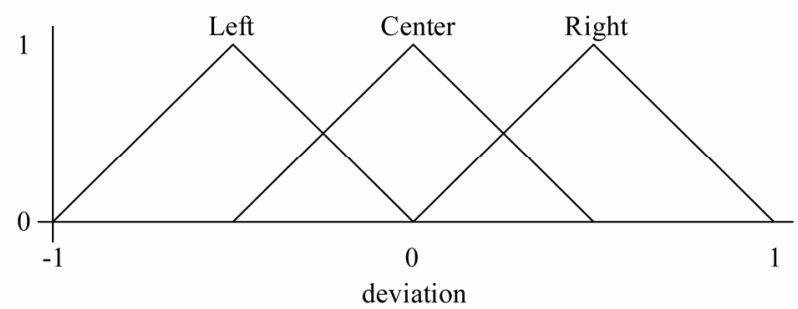

Figure 5. Membership function position deviation and load angle deviation.

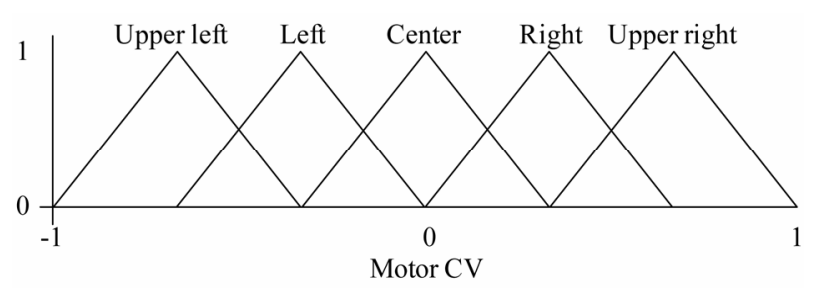

Figure 6. Membership function motor $\mathrm{CV}$.

rulebase which determines how the input membership functions are related to the output membership functions Table 2. displays the used rule base.

The rulebase can be read as follow. If the load angle deviation is left and the position deviation is center the motor CV will be right. Figure 7 gives a graphical representation of the behaviour of the fuzzy controller.

To make the system more flexible gains are connected to the fuzzy controller inputs and outputs ( $\mathrm{K}$ rod, $\mathrm{K}$ pos and $\mathrm{Kcv}$ ). With these gains the normalized membership functions can be stretched or compressed without changing the membership functions.

\subsection{Internal Model Controller}

The internal model controller shows the same behaviour as the parallel P-controller. The only difference is that the control actions are being performed on a digital
Table 2. Rulebase fuzzy controller.

\begin{tabular}{lcccc}
\hline & & \multicolumn{3}{c}{ Position deviation } \\
\cline { 3 - 5 } & & Left & Center & Right \\
\hline \multirow{2}{*}{$\begin{array}{l}\text { Load angle } \\
\text { deviation }\end{array}$} & Center & Left & Right & Upper right \\
& Right & Upper left & Center & Right \\
& & & &
\end{tabular}

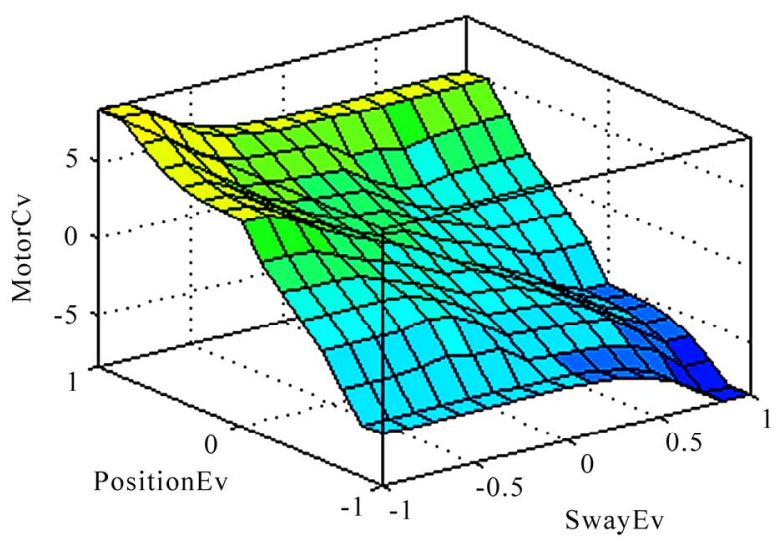

Figure 7. Fuzzy controller input-output relationships.

model instead of the process. The control signals are being based on the predicted behaviour of the process. Differences between the model and the process are fed back with a low pass filter. This type of controller is very suitable in cases where the sensors suffer from noise. Figure 8 is the block diagram of this controller.

\subsubsection{Discrete Motor Model}

Equation (6) is transferred to the z-domain by applying the following function

$$
s=\frac{z-1}{T z}
$$




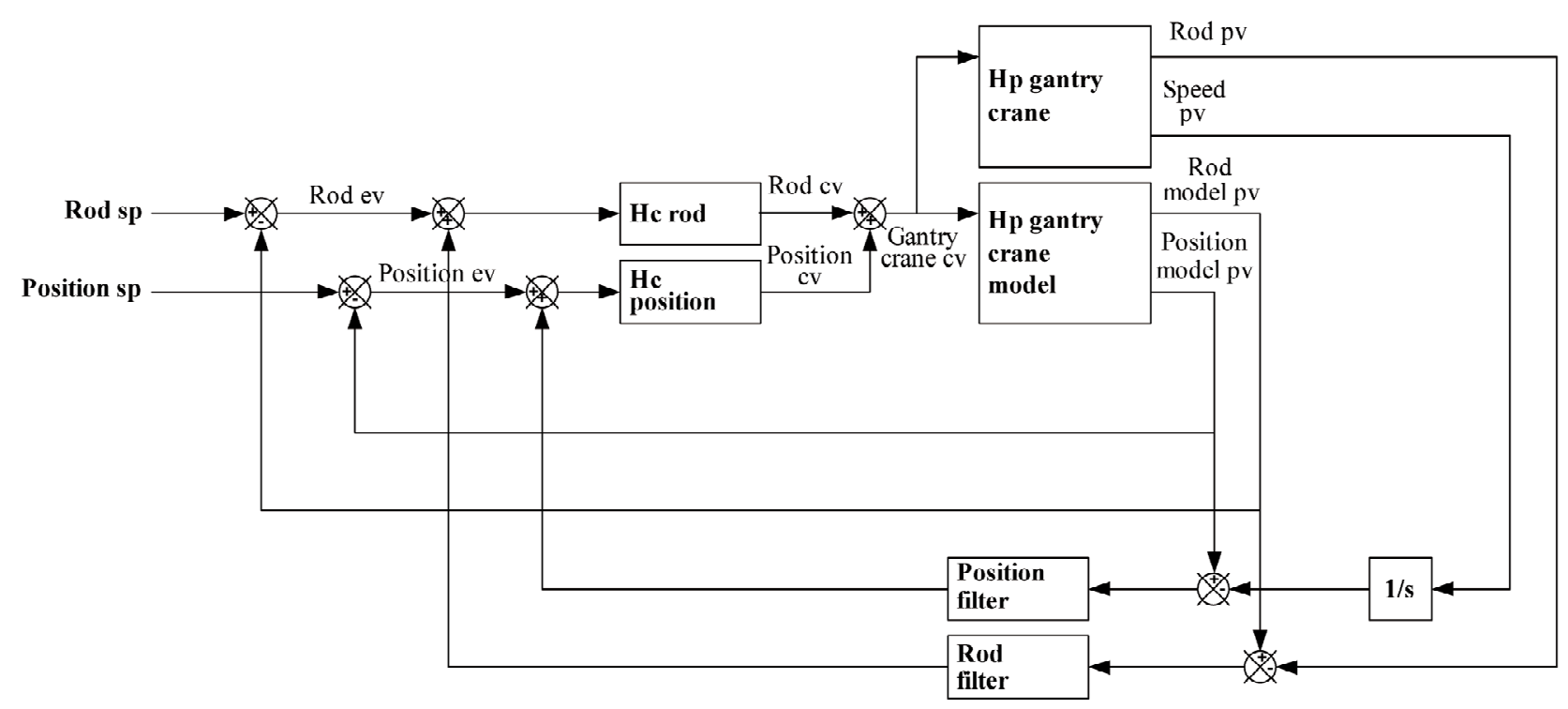

Figure 8. Block diagram of the internal model controller.

Where $\mathrm{T}$ is the sample rate. This results in the following discrete transfer function

$$
\frac{K_{m} T^{2} z^{2}}{J L z^{2}-2 J L z+J L+J R T z^{2}-J R T z+K_{b} K_{m} T^{2} z^{2}}
$$

This is equal to $\mathrm{x} / \mathrm{u}$ resulting in the following relationship

$$
\begin{aligned}
& x J L z^{2}-2 x J L z+x J L+x J R T z^{2}-x J R T z \\
& +x K_{b} K_{m} T^{2} z^{2}=u K_{m} T^{2} z^{2}
\end{aligned}
$$

After some simplification and adaptation for implementation the relationship between input and output can be rewritten as

$$
x=\frac{u K_{m} T^{2}+2(L J+J R T) x z^{-1}-L J x z^{-2}}{L J+J R T+K_{b} K_{m} T^{2}}
$$

\subsubsection{Discrete Mass Model}

The model of the mass as in formula (15) has a differential action. To simplify the digital model the differential action is shifted to the discrete movement model and the discrete load model. In this way the model shows no dynamics and therefore can directly being applied in the discrete domain.

$$
\frac{\frac{F}{S}}{\omega}=\frac{E f f_{\text {pulley }} J}{R_{\text {pulley }}}
$$

\subsubsection{Discrete movement model}

Next part to be transferred to the discrete time domain is the transfer function of the movement of the motor. A transfer function for a static load has to be created. Formula (16) is used without the movement of the load

$$
M \frac{d v}{d t}+m \frac{d v}{d t}=u
$$

Then this function is transferred to the s-domain

$$
(M+m) s v=u
$$

Resulting in the following transfer function

$$
\frac{v}{u}=\frac{1}{(M+m) s}
$$

Taken into account that the result of the discrete mass model as described in formula (25) is the integral of $u$, the transfer function can be rewritten as

$$
\frac{x}{u}=\frac{1}{(M+m) s}
$$

Formula (21) is applied on this transfer function to transfer it to the $\mathrm{z}$-domain resulting in the following discrete transfer function

$$
\frac{x}{u}=\frac{T z}{(M+m)(z-1)}
$$

This is equal to $\mathrm{x} / \mathrm{u}$ resulting in the following relationship

$$
x(m+M)(z-1)-u T z
$$

After some simplification and adaptation for implementation the relationship between input and output can be rewritten as

$$
x=\frac{u T+(m+M) x z^{-1}}{m+M}
$$

\subsubsection{Discrete Load Model}

Next part to be transferred to the discrete time domain is 
the transfer function of the angle of the load. Taken into account that the result of the discrete mass model is the integral of $u$, the transfer function as in formula (20) can be rewritten as

$$
-\frac{s}{l M s^{2}+g(m+M)}
$$

Formula (21) is applied on this transfer function to transfer it to the z-domain resulting in the following discrete transfer function

$$
-\frac{T z(z-1)}{l M z^{2}-2 l M z+l M+g(m+M) T^{2} z^{2}}
$$

This is equal to $\mathrm{x} / \mathrm{u}$ resulting in the following relationship

$$
x\left(l M z^{2}-2 l M z+l M+g(m+M) T^{2} z^{2}\right)=-u T z(z-1)
$$

After some simplification and adaptation for implementation the relationship between input and output can be rewritten as

$$
x=\frac{-u T+u T z^{-1}+2 x l M z^{-1}-x l M z^{-2}}{l M+g(m+M) T^{2}}
$$

\subsubsection{Total Discrete Model}

The total digital model is the result of the block diagram of formulas as displayed in Figure 9.

\section{Simulation}

The control algorithms were tested in Matlab Simulink.
Figure 10 shows the setup for the simulation of the gantry crane.

Table 3 shows the parameter list used for the simulation.

Figure 11 shows the result when applying a step of $0.2 \mathrm{~V}$ on the Gantry crane.

Next the controllers are simulated. Table 4, 5, 6 and 7 shows the parameter list with controller settings

Figure 12 shows the result when a step of 0.4 is applied on the position SP for all the controllers.

The performance for all the controllers are shown in Table 8.

When comparing the simulated controllers the similarity between the parallel P-controller and the cascade $\mathrm{P}$-controller is obvious. The performance and the step response are almost the same.

The fuzzy controller is showing the best performance. This is mainly caused by the fact that the Gantry Crane $\mathrm{CV}$ is limited by the output membership function of the fuzzy controller. At the other controllers only the saturation of the actuators are limiting the Gantry Crane CV. Limiting is important because a large $\mathrm{dCV} / \mathrm{dt}$ will cause large oscillations on the rod angle.

The internal model controller is showing the worst performance, although the differences are small. Important factor is that the time constant of the rod angle filter is larger then the time constant of the rod angle. Therefore the controller is not able to correct the differences between model and process fast enough. When reducing the time constant of the filter the influence of the model will be reduced and the system will be more vulnerable for noise. Figure $\mathbf{1 3}$ show the difference between the simulated process and the digital model.

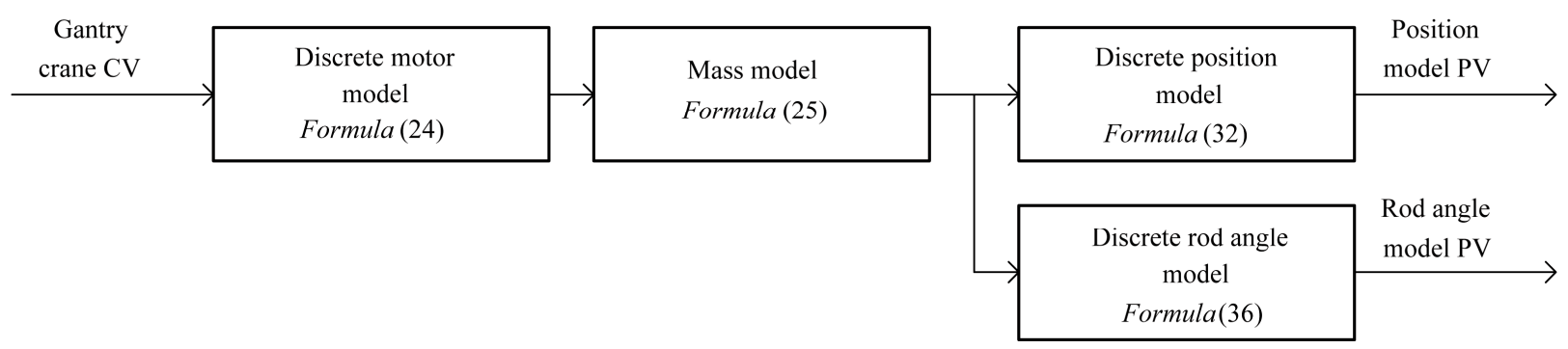

Figure 9. Gantry crane digital model overview.

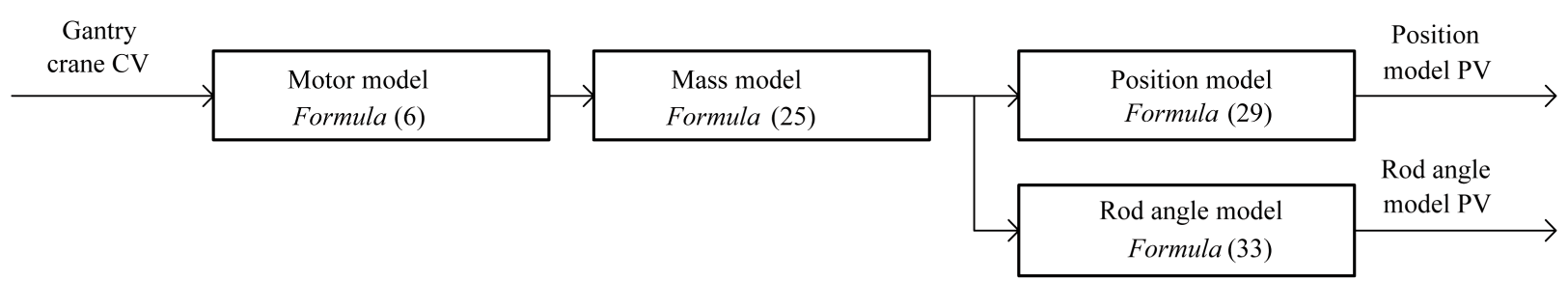

Figure 10. Gantry crane model overview. 

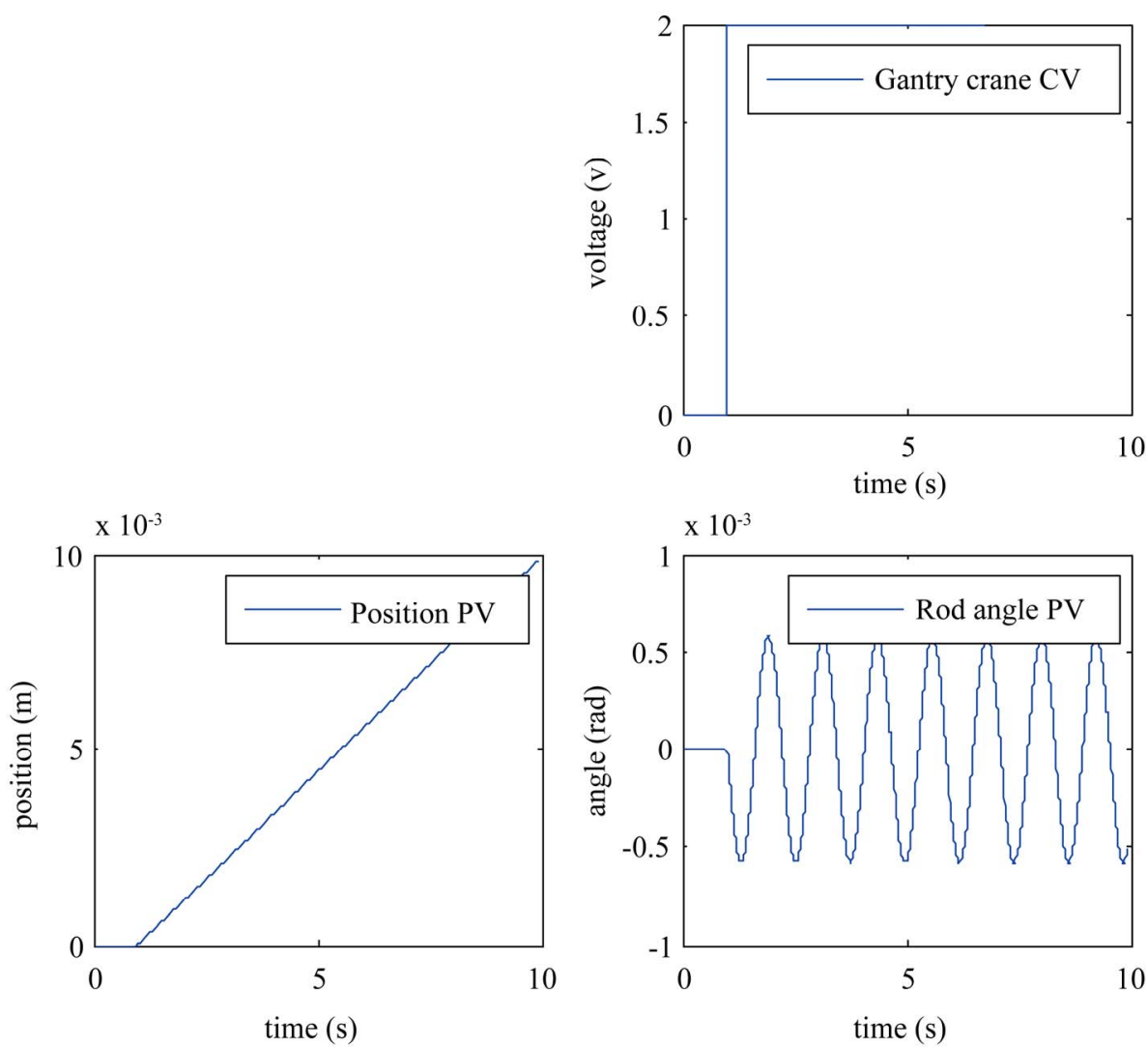

Figure 11. Gantry crane step response.
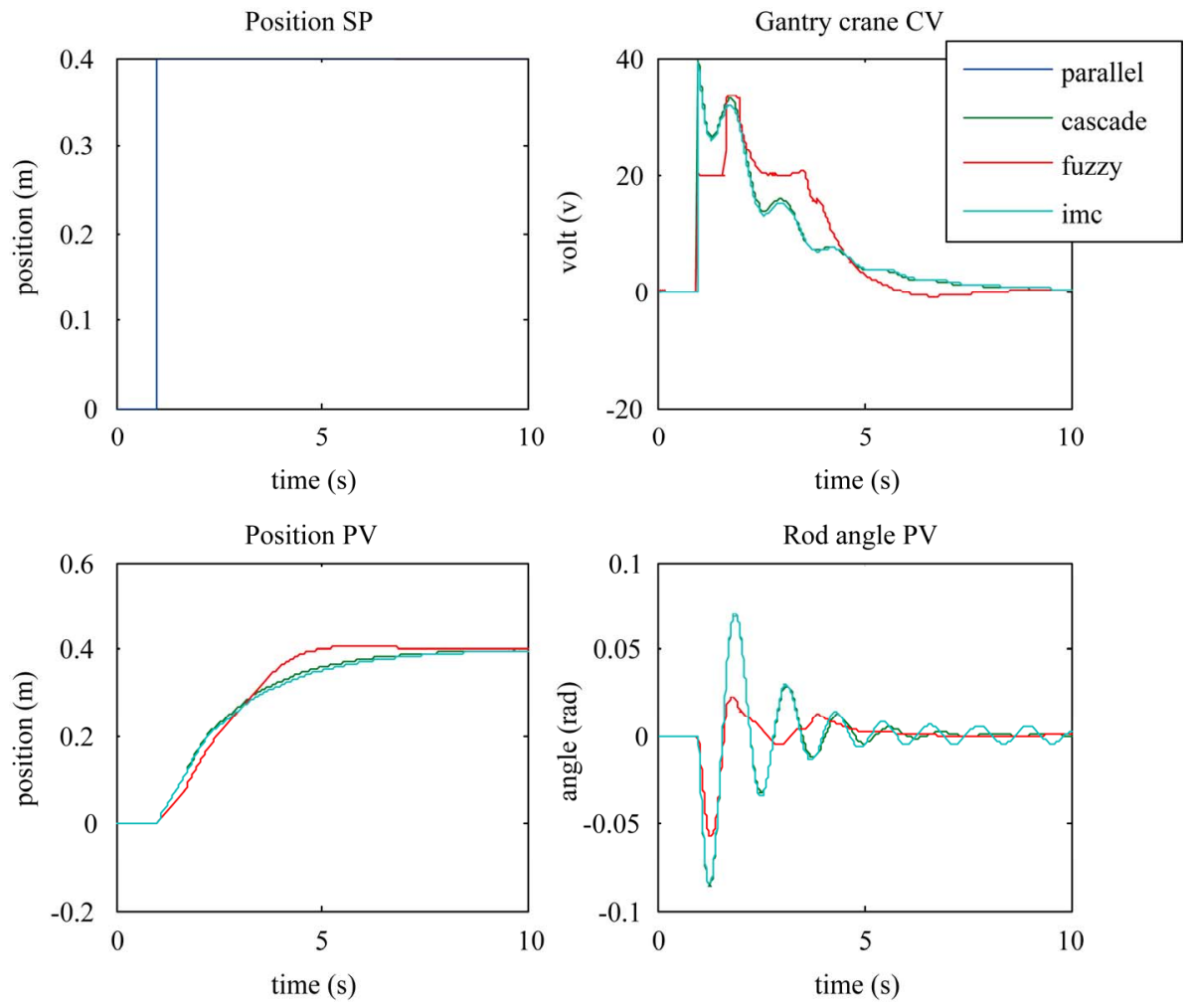

Figure 12. Gantry crane simulated controllers step response. 

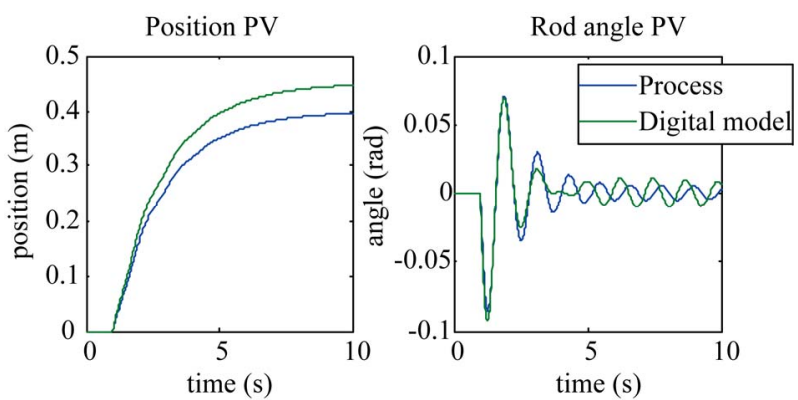

Figure 13. Gantry crane difference simulated process and digital model.

Table 3. Simulation parameter list.

\begin{tabular}{lcc}
\hline $\mathrm{R}$ & $1.5 \Omega$ & Motor resistance \\
$\mathrm{L}$ & $0.004629 \mathrm{H}$ & Motor inductance \\
$\mathrm{K}_{\mathrm{b}}$ & 0.583 & Motor back EMF constant \\
$\mathrm{K}_{\mathrm{m}}$ & 0.711 & Motor torque constant \\
$\mathrm{J}$ & $3.14 * 10^{-4} \mathrm{~kg} \cdot \mathrm{m}^{2} / \mathrm{s}^{2}$ & Motor inertia \\
Eff & 0.98 & Pulley efficiency \\
$\mathrm{R}_{\text {Pulley }}$ & $0.03183 \mathrm{~m}$ & Pulley radius \\
$\mathrm{m}$ & $0.9906 \mathrm{~kg}$ & Mass of the load \\
$\mathrm{M}$ & $2.0225 \mathrm{~kg}$ & Mass of the crane \\
$\mathrm{l}$ & $0.55 \mathrm{~m}$ & Length of the rod \\
$\mathrm{g}$ & $9.81 \mathrm{~m} / \mathrm{s}^{2}$ & Gravitation constant \\
\hline
\end{tabular}

Table 4. Simulation parameter list parallel P-controller.

\begin{tabular}{lcc}
\hline Hc rod & -100 & Gain of the rod controller \\
Hc position & 100 & Gain of the position controller \\
\hline
\end{tabular}

Table 5. Simulation parameter list cascade P-controller.

\begin{tabular}{lcc}
\hline Hc rod & 100 & Gain of the rod controller \\
Hc position & 1 & Gain of the position controller \\
\hline
\end{tabular}

Table 6. Simulation parameter list fuzzy controller.

\begin{tabular}{lcc}
\hline K rod & 50 & Gain for the rod membership function \\
K pos & 10 & Gain for the position membership function \\
Kcv & 4 & Gain for the output membership function \\
\hline
\end{tabular}

Table 7. Simulation parameter list internal model controller.

\begin{tabular}{lcc}
\hline Hc rod & -100 & Gain of the rod controller \\
Hc position & 100 & Gain of the position controller \\
Position filter & 0.01 & output $_{\text {new }}=0.01 \cdot$ input $+0.99 \cdot$ output $_{\text {old }}$ \\
Rod filter & 0.1 & output $_{\text {new }}=0.1 \cdot$ input $+0.9 \cdot$ output $_{\text {old }}$ \\
\hline
\end{tabular}

\section{Validation}

Next step in the process is the validation of the controllers in Labview on the Gantry Crane scale model.

The input signals were suffering from a large amount of noise. Figure 14 gives an impression of the noise at the angle sensor.

The decision was made to implement only a rate of change limiter with a maximum change rate of 0.1 for the noise. The main reason was that a low pass filter will introduce a phase shift in the measurements influencing the controller. This would make a proper comparison of the control algorithms more difficult. In the final application filtering, of course, has to be taken into account.

\subsection{Validation of Parallel P-Controller}

First the parallel P-controller was validated. Table 9 shows the parameter list with controller settings.

Figure 15 shows the result when a step of 0.4 is applied on the position SP.

Table 10 shows the performance of the controller. The settling time for the rod angle is an approximate value due to the drift and noise in the measurement signal.

Table 8. Performance simulated controllers.

\begin{tabular}{|c|c|c|c|c|}
\hline & Parallel controller & Cascade controller & Fuzzy controller & Internal model controller \\
\hline Position overshoot & $0 \%$ & $0 \%$ & $1.5 \%$ & $0 \%$ \\
\hline Position settling time (95\%) & $6.31 \mathrm{~s}$ & $6.33 \mathrm{~s}$ & $4.35 \mathrm{~s}$ & $6.86 \mathrm{~s}$ \\
\hline Rod angle overshoot & 0.085 & 0.086 & 0.057 & 0.084 \\
\hline Rod angle settling time $(0.01)$ & $4.51 \mathrm{~s}$ & $4.49 \mathrm{~s}$ & $4.07 \mathrm{~s}$ & $4.46 \mathrm{~s}$ \\
\hline
\end{tabular}




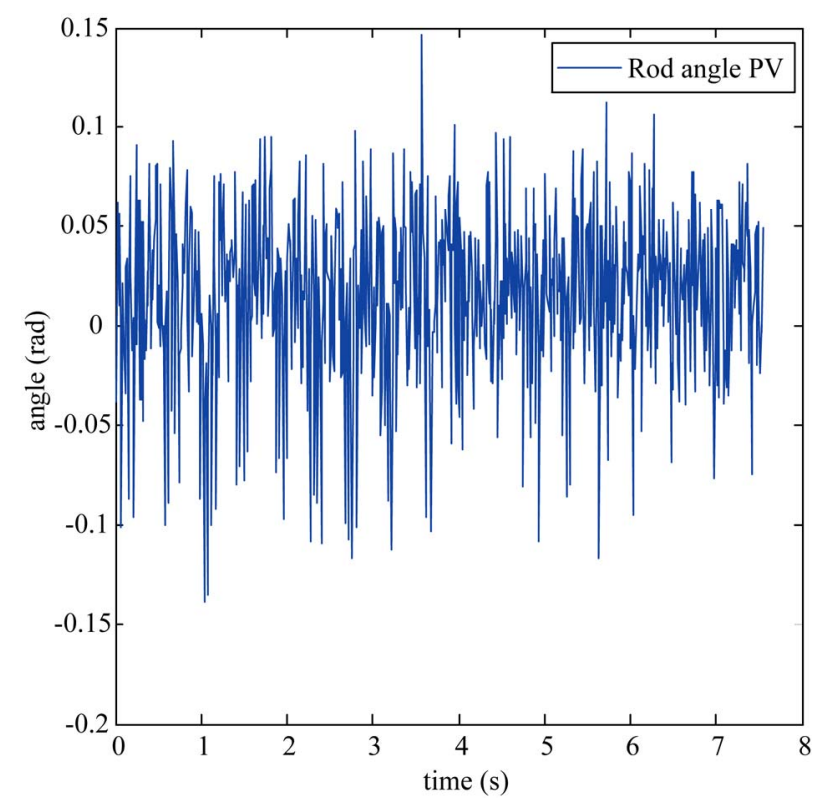

Figure 14. Angle sensor noise.

Table 9. Validation parameter list parallel P-controller.

\begin{tabular}{lcc}
\hline Hc rod & -5 & Corrected gain of the rod controller \\
Hc position & 100 & Corrected gain of the position controller \\
\hline
\end{tabular}

Table 10. Performance validated parallel P-controller.

\begin{tabular}{lc}
\hline Position overshoot & $0 \%$ \\
Position settling time (95\%) & $7.24 \mathrm{~s}$ \\
Rod angle overshoot & 0.36 \\
Rod angle settling time (0.01) & $8.3 \mathrm{~s}$ \\
\hline
\end{tabular}

The rod controller is far more vulnerable for noise on the sensor then the position controller. This is mainly caused by the fact that the position controller is using the integral of the sensor and the rod controller is using the sensor directly. For this reason the gain of the rod controller compared to the simulation is decreased drastically to avoid large oscillation caused by the sensors.

\subsection{Validation of cascade P-controller}

Next the cascade P-controller was validated. Table 11 shows the parameter list with controller settings.

Figure 16 shows the result when a step of 0.4 is applied on the position SP.

Table 12 shows the performance of the controller. The settling time for the rod angle is an approximate value due to the drift and noise in the measurement signal.
From this controller the same conclusions can be made as with the parallel controller. Due to the fact that the control loops are cascaded retuning of both the rod controller and the position controller has been changed. To make the system less vulnerable for noise, the gain of the rod controller compared to the simulation is decreased drastically. To improve the settling time the gain of the position controller is therefore being increased.

\subsection{Validation of Fuzzy Controller}

Next the fuzzy controller was validated. Table $\mathbf{1 3}$ shows the parameter list with controller settings.

Figure 17 shows the result when a step of 0.4 is applied on the position SP.

Table 14 shows the performance of the controller. The settling time for the rod angle is an approximate value due to the drift and noise in the measurement signal.

Also for the fuzzy controller retuning was necessary due to the sensor noise. Especially the gain for the rod membership function was decreased compared to the simulation. Because of the fact that the position membership function is independent of the rod membership

Table 11. Validation parameter list cascade P-controller.

\begin{tabular}{lll}
\hline Hc rod & 5 & Corrected gain of the rod controller \\
Hc position & 20 & Corrected gain of the motor controller \\
\hline
\end{tabular}

Table 12. Performance validated cascade P-controller.

\begin{tabular}{lc}
\hline Position overshoot & $0 \%$ \\
Position settling time (95\%) & $7.65 \mathrm{~s}$ \\
Rod angle overshoot & 0.38 \\
Rod angle settling time (0.01) & $9.7 \mathrm{~s}$ \\
\hline
\end{tabular}

Table 13. Validation parameter list fuzzy controller.

\begin{tabular}{ccc}
\hline K rod & 1 & Gain for the rod membership function \\
K pos & 10 & Gain for the position membership function \\
Kcv & 5 & Gain for the output membership function \\
\hline
\end{tabular}

Table 14. Performance validated fuzzy controller.

\begin{tabular}{ll}
\hline Position overshoot & $0 \%$ \\
Position settling time $(95 \%)$ & $3.99 \mathrm{~s}$ \\
Rod angle overshoot & 0.36 \\
Rod angle settling time $(0.01)$ & $7.0 \mathrm{~s}$ \\
\hline
\end{tabular}



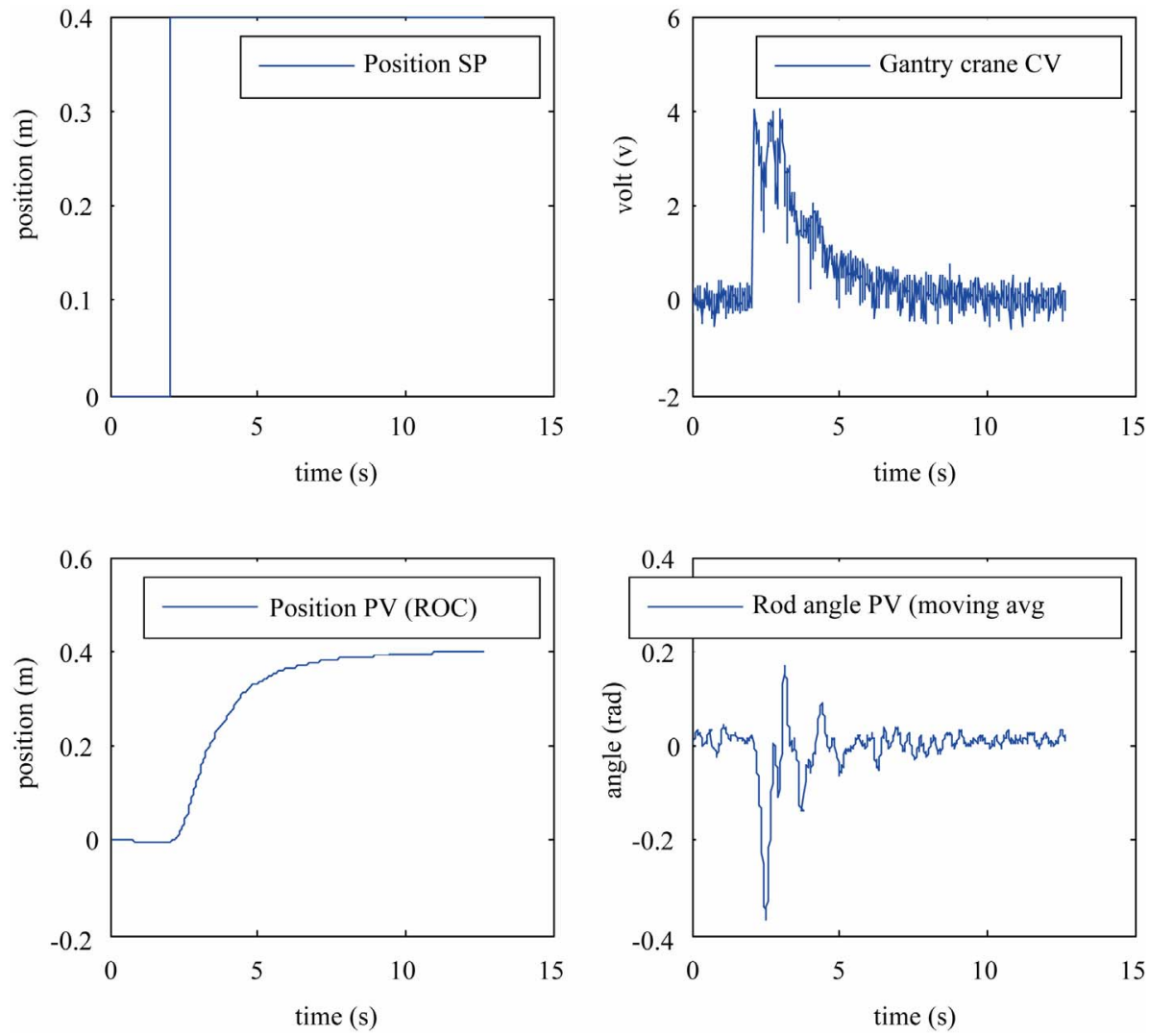

Figure 15. Gantry crane validated parallel P-controller step response.
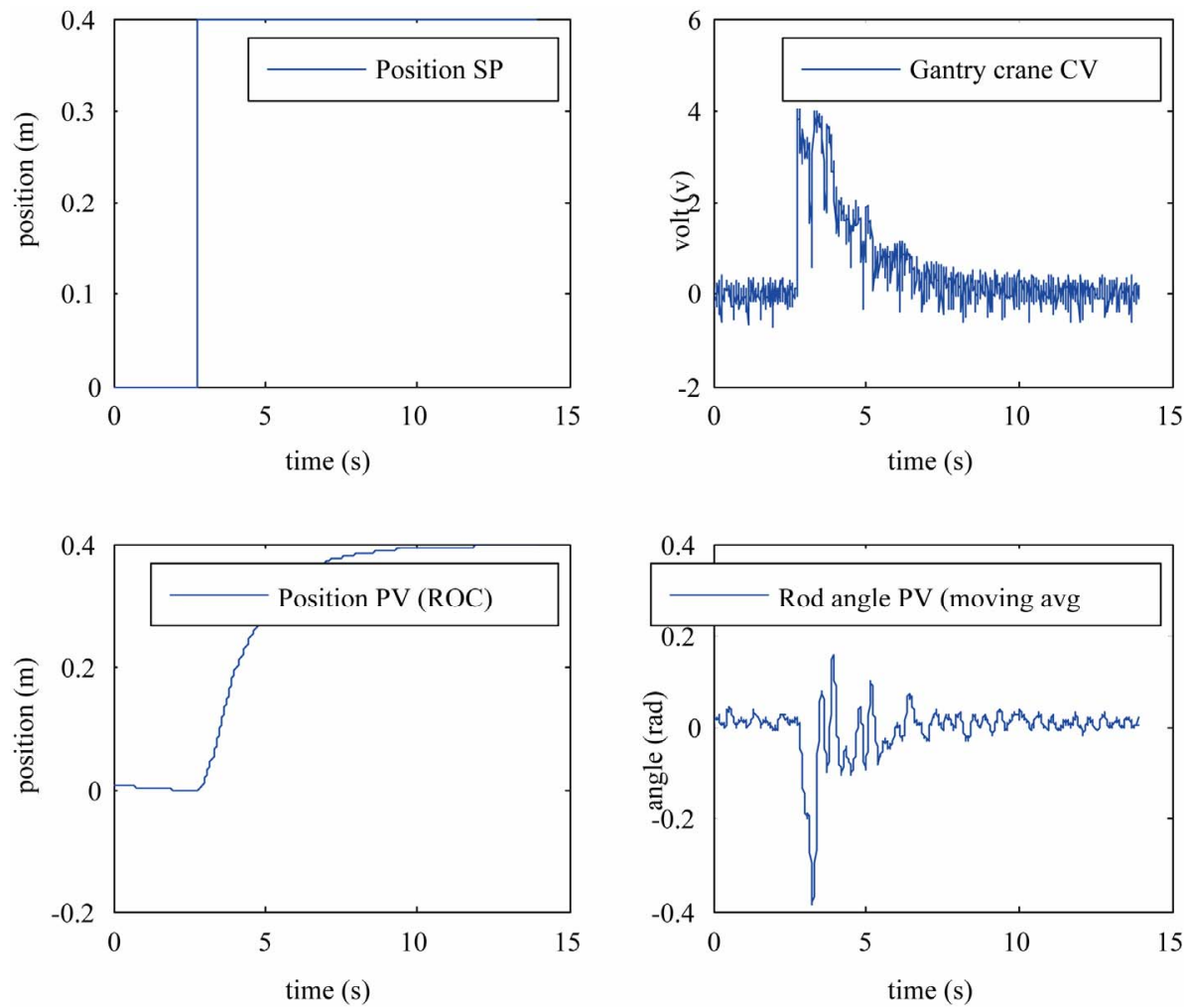

Figure 16. Gantry crane validated cascade P-controller step response. 

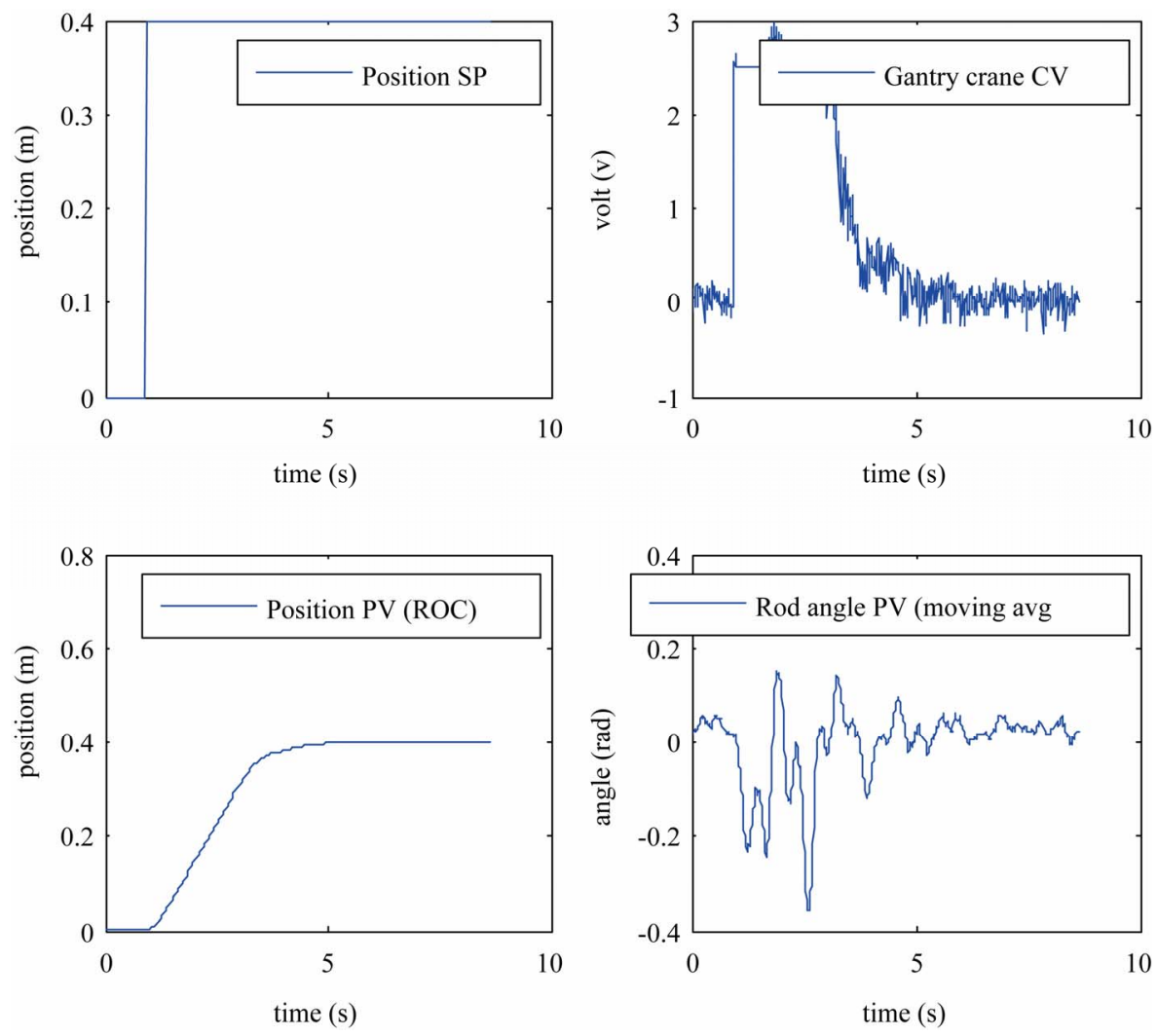

Figure 17. Gantry crane validated fuzzy controller step response.

function no retuning for this part was necessary. The output membership function was increased to improve the settling time of the controller.

\subsection{Validation of Internal Model Controller}

Next the internal model controller was validated. Table 15 shows the parameter list with controller settings.

Figure 18 shows the result when a step of 0.4 is applied on the position SP.

Table 16 shows the performance of the controller. The settling time for the rod angle is an approximate value due to the drift and noise in the measurement signal.

In this case the rod angle will not settle. Main cause is the difference between the model and the process. Figure 19 shows the difference between the model and the process.

Although some filtering is done by this controller for the control of the rod angle some sensitivity for sensor noise still exists, therefore the gain of the rod controller was decreased compared to the simulation. The time constant for the position filter was decreased to improve the settling time.

The same problem as described in the simulation regarding the time constant of the filter compared to the process arises here. Decreasing the time constant of the rod filter is a logical solution but the disadvantage is the increased sensitivity for noise which original was the biggest advantage of this type of controller. In the step response this can be seen by the reduced oscillation on the gantry crane $\mathrm{CV}$ when comparing this controller to the other controllers.

Table 15. Validation parameter list internal model controller.

\begin{tabular}{lcl}
\hline Hc rod & -5 & Gain of the rod controller \\
Hc position & 100 & Gain of the motor controller \\
Position filter & 0.1 & output $_{\text {new }}=0.1 \cdot$ input $+0.9 \cdot$ output $_{\text {old }}$ \\
Rod filter & 0.1 & output $_{\text {new }}=0.1 \cdot$ input $+0.9 \cdot$ output $_{\text {old }}$ \\
\hline
\end{tabular}

Table 16. Performance validated internal model controller.

\begin{tabular}{lc}
\hline Position overshoot & $0 \%$ \\
Position settling time $(95 \%)$ & $8.39 \mathrm{~s}$ \\
Rod angle overshoot & 0.34 \\
Rod angle settling time $(0.01)$ & N.A. \\
\hline
\end{tabular}



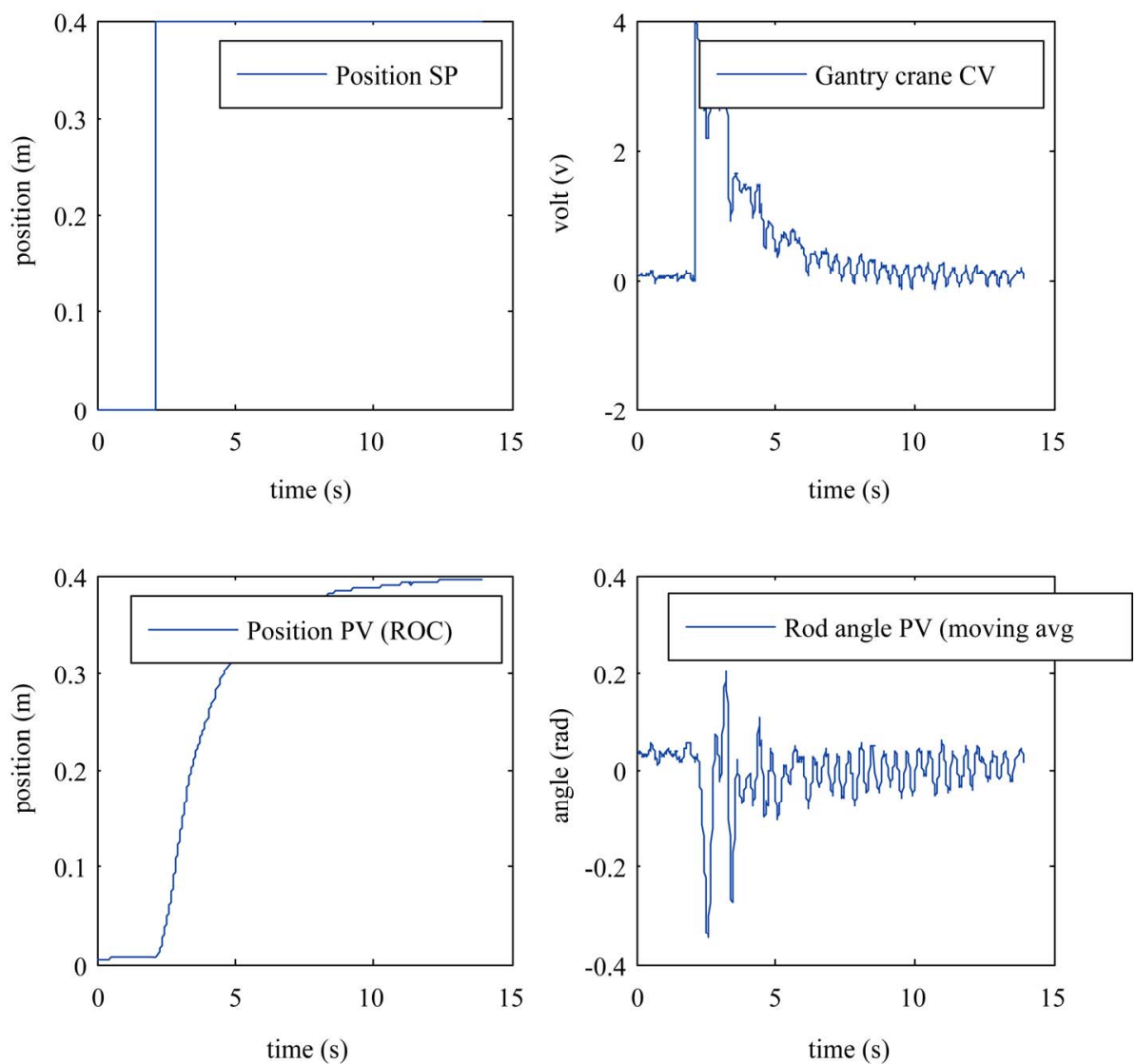

Figure 18. Gantry crane validated internal model controller step response.

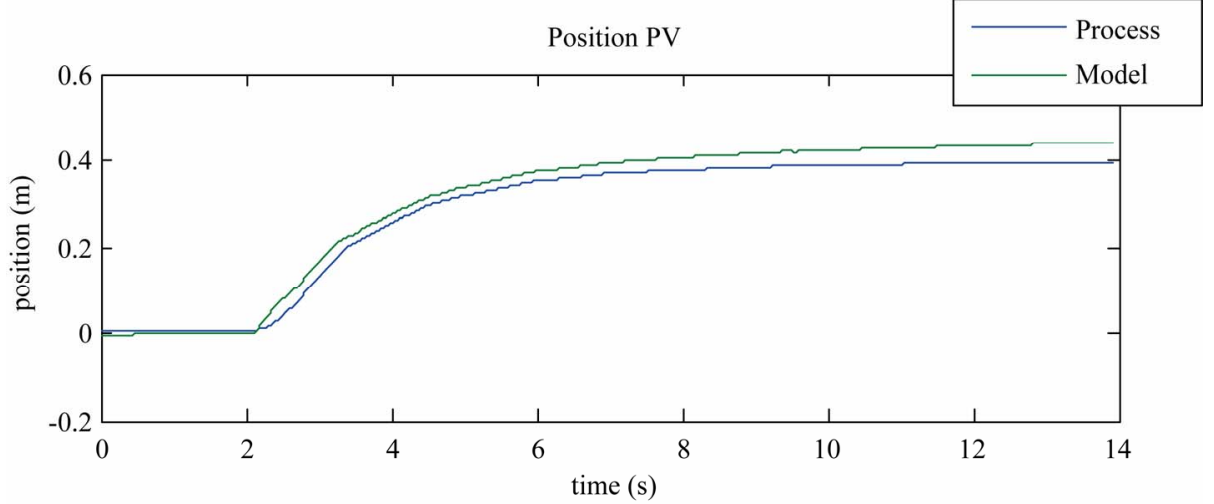

Rod angle PV

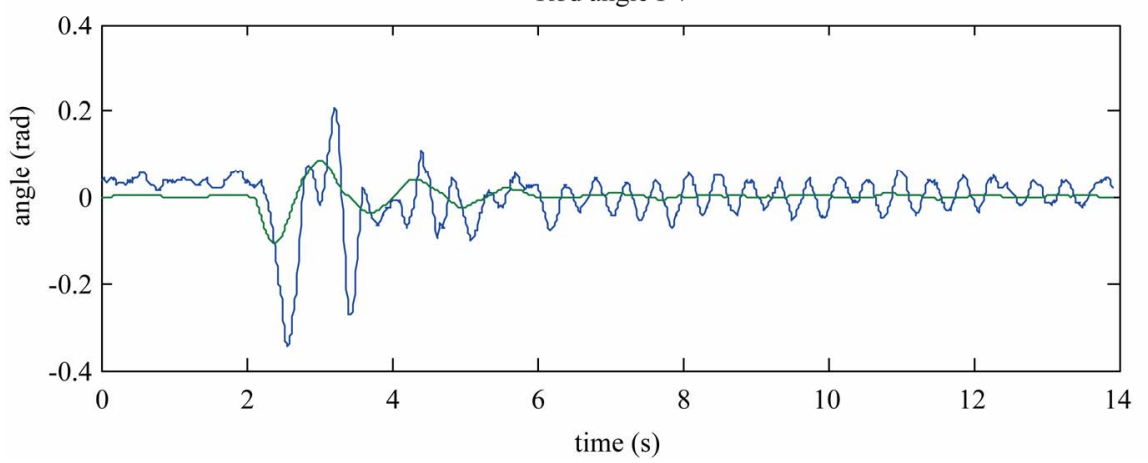

Figure 19. Gantry crane validated internal model controller process and model difference. 


\subsection{Comparison}

Globally the comparison of the validated controllers shows the same results as the simulated controllers. Again the results of the parallel P-controller and the cascade P-controller are comparable. Also the fuzzy controller is showing the best performance. These three controllers also suffer from the noise caused by the sensors because the sensor signals are only limited by a rate of change limiter.

In this case the biggest advantage of the internal model controller is demonstrated. The control action is performed on the model instead of the process and the deviation between the model and the process is being fed back through a filter. This makes the controller less sensitive to noise. The controller output therefore is showing less oscillation decreasing the wear on the actuator. A higher sampling rate on the measurement and the modelling can be a possible solution. But the biggest disadvantage is that these controllers can not handle oscillations smaller then the time constant of the rod filter.

\section{Conclusions}

Main conclusion is that all controllers except the internal model controller are capable in stabilizing the system and move a load on the gantry crane to a new position.

The biggest problem on the gantry crane scale model is the amount of noise on the rod angle measurement signal A solution could be to use an optical absolute encoder for this measurement, the signal is then already digital and therefore does not suffer from noise issues. The chosen resolution must be sufficient to measure small angle deviations.

The most elegant controller, the internal model controller, is performing the worst considering the damping of the rod movement. In this case the filter characteristics prevent correct damping. Higher oversampling and higher sample rate on the model will improve this issue.

The fuzzy controller is showing the fastest settling times and therefore performs best when choosing a controller based on these criteria. The most simple controller (parallel P-controller) is also performing well and is easier to implement on a platform then a relative complex fuzzy controller, therefore this is a practical alternative.

\section{References}

[1] S. J. Nordfjord and H. Pálsson, "LEGO-Crane Controller using RCX and RoboLab". http://fuzzy.iau.dtu.dk/ download/lego9/lego9.pdf

[2] M. A. Ahmad and A. N. K. Nasir, "Hybrid Input Shaping and LQR control schemes of a Gantry Crane System," Proceedings of the 3rd International Conference on Mechatronics, ICOM'08, pp. 365-372

[3] S. W. Su, H. Nguyen, R. Jarman, J. Zhu, D. Lowe, P. McLean, S. Huang, N. T. Nguyen, R. Nicholson and K. Weng, "Model Predictive Control of Gantry Crane with Input Nonlinearity Compensation," Proceedings of World Academy of Science, Engineering and Technology, Vol. 3, 8 february 2009, pp. 312-316.

[4] H. Butler, G. Honderd and J. van Amerongen, "Model Reference Adaptive Control of a Gantry Crane Scale Model," IEEE Control System, January 1991, pp. 57-62

[5] Wahyudi, J. Jalani, R. Muhida and M. J. E. Salami, “Control Strategy for Automatic Gantry Crane Systems: A Practical and Intelligent Approach," International Journal of Advanced Robotic Systems, Vol. 4, No. 4, (2007), pp 447-456

[6] P. Reading, "One-Degree of Freedom Internal Model Control," 2002, pp. 39-64. http://www.bgu.ac.il/chem eng/pages/Courses/oren $\% 20$ courses/Chapter $\% 203 \% 20-\%$ 20corrected $\% 2002$.pdf 